\title{
A diet rich in menhaden oil has the hypolipidemic effect but increases plasma glucose and insulin levels in rats
}

\author{
B. Dziedzic', E. Zgórzyńska, D. Bewicz-Binkowska and A. Walczewska \\ ${ }^{1}$ Medical University of Lodz, Department of Cell-to-Cell Communication, Mazowiecka 6/8, 92-215 Łódź, Poland
}

KEY WORDS: fish oil, high-fat diet, plasma lipids, glucose, insulin

Received: $\quad 15$ June 2018

Revised: 14 December 2018

Accepted: 27 February 2019

${ }^{1}$ Corresponding author:

e-mail: barbara.dziedzic@umed.lodz.pl

\begin{abstract}
A composition of dietary fat considerably affects the metabolism of nutrients, especially high-fat diet is associated with various metabolic disorders, diabetes and cardiovascular diseases in humans. Studies on rodents are an established model to investigate the pathophysiology of excessive fat in diets, hence the aim of the study was to evaluate the effect of dietary fats different in composition on plasma lipids, glucose and insulin levels in non-genetically modified rats instead of genetic models of obesity or diabetes. Animals were fed purified low- or high-fat (12 and 40\% energy from fat, respectively) diets containing the same fat sources - lard, sunflower oil or menhaden oil for six weeks. Feeding menhaden oil, both in low- and high-fat diets, resulted in decreased plasma triglyceride, total cholesterol and high-density lipoprotein cholesterol levels in comparison to diets composed of lard or sunflower oil. However, high-fat diet with menhaden oil caused an increase in plasma glucose and insulin levels, which resulted in the increased HOMA-IR (Homeostatic Model Assessment - Insulin Resistance) index in relation to low-fat diet with the same oil. The obtained results demonstrate that high menhaden oil intake has the hypolipidemic effect but can impair glucose homeostasis in non-genetically modified rats.
\end{abstract}

\section{Introduction}

High-fat intake is a recognized risk factor for dyslipidemia and metabolic disorders leading to cardiovascular diseases, obesity and type 2 diabetes mellitus (Baum et al., 2012; Silva Figueiredo et al., 2017). However, the ultimate effect of a high-fat diet on the lipid and glucose metabolism, beside genetic background, depends on a dietary fat composition. A diet high in saturated fatty acids exerts more deleterious effect on fat metabolism than diet containing high amount of polyunsaturated fatty acids (PUFAs). Excessive ingestion of animal fat induces weight gain, hyperlipidemia (Siri-Tarino et al., 2010) and insulin resistance in humans (Silva Figueiredo et al., 2017), and in animals (Buettner et al., 2007). However, a beneficial effect of n-3 PUFAs on plasma triglycerides and lipoprotein levels (Baum et al., 2012), in part by the regulation of gene expression of the enzyme involved in fatty acid oxidation and lipoprotein metabolism (Jump et al., 2013), was demonstrated in the literature.

Studies evaluating the effect of PUFAs on glucose metabolism and insulin sensitivity yielded divergent results. It has been shown in animals that ingestion of high amount of n-6 PUFAs increased (Lee et al., 2006), or decreased insulin sensitivity (Tekeleselassie et al., 2014), or was positively correlated with obesity and insulin resistance (Cameron and Ghosh, 2013). Regarding n-3 PUFAs, dietary intervention showed their beneficial role in the prevention of insulin resistance (Liu et al., 2013), 
and reversion of insulin resistance (Lanza et al., 2013) induced by a high-fat diet in rodents. The clinical studies demonstrated more divergent effects of n-3 PUFAs on glucose metabolism. In healthy humans, a high-fat diet rich in n-3 PUFAs was not able to change tissue insulin sensitivity (Akinkuolie et al., 2011). In relation to type 2 diabetes mellitus prevention by $\mathrm{n}-3$ PUFAs, a lowering prevalence was confirmed by the meta-analysis (Chen et al., 2017). On the other hand, the newest analysis of current clinical data did not confirm improving glycemic control by $n-3$ PUFA supplementation in the diabetic patients (Itsiopoulos et al., 2018).

The effects of dietary fats on glucose and lipid metabolism and metabolic syndrome-related disorders are strongly associated with the amount and composition of ingested fat. Hence, the aim of the present study was to evaluate the effect of different fats in low- and high-fat diets, both composed with either lard as a source of saturated and monounsaturated fatty acids, with sunflower oil, as a source of n-6 PUFAs, or with menhaden oil as a source of n-3 PUFAs, on plasma lipids, glucose and insulin levels in non-genetically modified rats.

\section{Material and methods}

\section{Animals and diets}

The protocol of the experiment was reviewed and approved by the Ethical Committee for Animal Care of Medical University of Lodz (Poland), No. ŁB111.

Sixty male Wistar non-genetically modified rats weighting 140-150 g (the Animal House of Polish Academy of Sciences Medical Research Center, Warsaw, Poland) were acclimatized for one week at the animal facility in controlled temperature $(23 \pm$ $\left.1{ }^{\circ} \mathrm{C}\right)$ and humidity $(55 \pm 5 \%)$ with air-cycle changes (15 fresh air changes per $1 \mathrm{~h}$ ) and a $12 \mathrm{~h}$ light-dark cycle (light from 06:00). Animals were housed in plastic shoeboxes with stainless steel wired bottom with free access to a standard diet (Motycz, Poland) and water ad libitum. Rats were randomly assigned to six feeding groups ( $\mathrm{n}=10$ per group). Three groups were fed low-fat diets ( $12 \%$ energy from fat) prepared with lard, sunflower oil or menhaden oil, and three groups were fed high-fat diets ( $40 \%$ energy from fat) containing the same fat sources. The composition of the purified diets is presented in Table 1. The menhaden oil diets were supplemented with soybean oil to maintain adequate intake of essential n-6 PUFAs. The fatty acid composition of lard was determined by gas-liquid chromatography at the
Table 1. Composition of purified diets

\begin{tabular}{|c|c|c|c|c|}
\hline \multirow{2}{*}{ Diet ingredients } & \multicolumn{2}{|c|}{ Low-fat diet } & \multicolumn{2}{|c|}{ High-fat diet } \\
\hline & $\mathrm{g} / \mathrm{kg}$ & \% energy & $\mathrm{g} / \mathrm{kg}$ & $\%$ energy \\
\hline Protein & 197.3 & 20.3 & 232.0 & 20.3 \\
\hline casein & 194.4 & & 228.6 & \\
\hline L-cystine $^{1}$ & 2.9 & & 3.4 & \\
\hline Carbohydrates & 655.9 & 67.5 & 453.7 & 39.7 \\
\hline corn starch ${ }^{2}$ & 364.4 & & 252.6 & \\
\hline sucrose & 291.5 & & 201.1 & \\
\hline $\mathrm{Fat}^{3}$ & 52.5 & 12.2 & 203.4 & 40 \\
\hline Cellulose ${ }^{4}$ & 48.6 & & 57.1 & \\
\hline AIN-93 Mineral Mix ${ }^{5}$ & 34.0 & & 40.0 & \\
\hline AIN-93 Vitamin Mix ${ }^{5}$ & 9.7 & & 11.4 & \\
\hline Choline bitartrate $^{1}$ & 1.9 & & 2.3 & \\
\hline Energy content, kcal/g & 3.93 & & 4.58 & \\
\hline
\end{tabular}

${ }_{1}^{1}$ Sigma-Aldrich (St. Louis, MO, USA); ${ }^{2}$ Stobimyl XMH 042 (Stockmeier Food, Herford, Germany); ${ }^{3}$ Fats: lard (Pamso, Pabianice, Poland), menhaden oil (Omega Protein, Inc., Reedville, VA, USA), sunflower oil (Fat Processing, Warsaw, Poland); ${ }^{4}$ Arbocel (J. Rettenmaier \& Söhne, Rosenberg, Germany); ${ }^{5}$ Research Diets, Inc. (New Brunswick, NJ, USA)

National Food and Nutrition Institute (Warsaw, Poland). The composition of fatty acids in sunflower oil and menhaden oil was provided by suppliers (Table 2). Diets were prepared as previously described (Dziedzic et al., 2007) and stored in daily rations in sealed bags at $-20{ }^{\circ} \mathrm{C}$. Purified diets were supplied daily at 15:00, and daily food intake was recorded and corrected for spillage $( \pm 0.1 \mathrm{~g})$. Rats were weighted 3 times per week. After 6 weeks of feeding and overnight fasting animals were anesthetized with ketamine and xylazine (i.p. 20 and $10 \mathrm{mg} / \mathrm{kg}$, respectively), blood was collected by cardiac puncture and centrifuged ( $5 \mathrm{~min}, 3000 \mathrm{~g}$ ), then plasma was aliquoted and stored at $-80{ }^{\circ} \mathrm{C}$ for analysis. The livers were dissected and weighted.

Table 2. Fatty acid composition of dietary fats

\begin{tabular}{lcrr}
\hline \multirow{2}{*}{ Fatty acids } & Lard & Sunflower oil & Menhaden oil \\
\cline { 2 - 4 } & \% by weight & & \\
\hline Saturated & 42.98 & 9.22 & 31.50 \\
Monounsaturated & 50.33 & 30.45 & 29.40 \\
Polyunsaturated n-6 & 6.27 & 59.52 & 7.91 \\
Polyunsaturated n-3 & 0.19 & 0.55 & 30.70 \\
n-3:n-6 ratio & 0.03 & 0.01 & 3.88 \\
\hline
\end{tabular}

\section{Biochemical determinations and HOMA-IR index}

Total cholesterol (TC), high-density lipoprotein (HDL) cholesterol, triglycerides (TG), and glucose levels in plasma were measured by enzymatic methods in the biochemical analyser Beckman Coulter AU480 (Beckman Coulter, Inc., Brea, CA, USA). 
The low-density lipoprotein (LDL) cholesterol level was calculated using the Friedewald's equation. Plasma insulin level was determined using the rat insulin RIA kit (CIS Bio International, Saclay, France), its sensitivity was $0.036 \mathrm{ng} / \mathrm{ml}$, and range $0.61-$ $150 \mathrm{ng} / \mathrm{ml}$. For a measurement of non-esterified free fatty acids (NEFA) a NEFA-C test (Wako Chemical, Osaka, Japan) was used. In brief, the samples were treated with acyl-CoA synthetase to form thiol esters. Then the acyl-CoA was oxidized and hydrogen peroxide was produced. In the presence of peroxidase after the oxidative condensation of 3-methyl-N-ethyl-N( $\beta$-hydroxyethyl)-aniline with 4-aminoantipyrine a purple coloured end product was measured colourimetrically at $550 \mathrm{~nm}$ with the use of spectrophotometer Ultraspeck III (Pharmacia LKB, Stockholm, Sweden). The HOMA-IR (Homeostatic Model Assessment - Insulin Resistance) index was calculated using the formula:

$$
\begin{gathered}
\text { HOMA-IR }=\text { fasting glucose }(\mathrm{mmol} / \mathrm{l}) \times \text { fasting } \\
\text { insulin }(\mu \mathrm{U} / \mathrm{ml}) / 22.5 .
\end{gathered}
$$

\section{Statistical analysis}

The results are expressed as mean \pm standard error of mean (SEM). The statistical analysis was performed using Graph-Pad Prism 6 software (GraphPad Software, San Diego, CA, USA). One-way analysis of variance (ANOVA) followed by the NewmanKeuls post hoc test was performed to evaluate the effects of fat type applied into the diets in the same amount (separately for low- and high-fat diets). Student's unpaired $t$-test was used for estimation of the difference between low- and high-fat diets based on the same fat type. A two-way ANOVA test was used to evaluate the interaction between fat level in diet (low- and high-fat diets) and fat type (lard, sunflower oil and menhaden oil). Statistical significance was considered at $P<0.05$.

\section{Results}

\section{Weight gain, food intake and liver mass}

The body weight gain of rats fed the isocaloric diets was associated with dietary fat source (Table 3). Lard was obesogenic in both, low- and high-fat diets, and body weight of rats fed diet with lard was significantly higher than that of rats fed diets with either sunflower or menhaden oils $(P<0.01$ and $P<0.001$, respectively). The highest weight gain in rats fed low-fat diet with lard did not correspond to the highest energy intake; however rats fed highfat diet with lard had the highest weight gain as well the highest caloric intake in comparison to the groups fed high-fat diets with other fat sources $(P<0.05$; Table 3$)$.

Macroscopic and microscopic examinations of livers from all groups of animals did not show any abnormalities. However, the relative liver weight of rats fed high-fat diets with sunflower or menhaden oil was significantly higher than that of rats fed the corresponding low-fat diets $(P<0.001$; Table 3$)$. Contrary, the relative liver weight was lower in rats fed high-fat diet with lard in comparison to animals fed low-fat diet with the same fat source $(P<0.001)$. Moreover the relative liver weight was lower in rats fed high-fat diet with lard than in rats fed high-fat diets with other oils $(P<0.05)$.

\section{Plasma lipids}

A six-week feeding of non-genetically modified rats with low- and high-fat diets with menhaden oil resulted in decreased plasma concentration of TG, TC and HDL cholesterol as compared to rats fed the isocaloric diets containing two other fats $(P<0.05$; Table 4). Moreover, the plasma concentrations of TG and TC in rats fed low-fat diet with menhaden oil were lowered by 44 and 16\%, respectively, and the HDL cholesterol concentration in rats fed highfat diet with menhaden oil was decreased by $24 \%$, also as compared to rats fed regular chow (data not shown). The plasma LDL cholesterol level did not differ between rats fed isocaloric diets regardless of used dietary fat source. However, in rats fed diets with sunflower or menhaden oils a tendency to decrease LDL cholesterol levels in comparison to rats fed the isocaloric diets with lard was shown. The plasma NEFA levels were slightly lowered in rats fed both high-PUFA diets in comparison to rats fed diet with lard $(P<0.05)$.

Two-way ANOVA showed that the fat type and fat level in diet (dietary group) had the independent effect on the examined plasma lipidemic parameters in rats (Table 5).

\begin{tabular}{|c|c|c|c|c|c|c|}
\hline \multirow{2}{*}{ Indices } & \multicolumn{3}{|l|}{$\underline{\text { Low-fat diets }}$} & \multicolumn{3}{|l|}{ High-fat diets } \\
\hline & lard & sunflower oil & menhaden oil & lard & sunflower oil & menhaden oil \\
\hline Body weight gain, $g$ & $154.0 \pm 5.0^{*}$ & $142.0 \pm 5.0$ & $132.0 \pm 5.5$ & $180.0 \pm 6.0^{\wedge}$ & $144.0 \pm 7.5$ & $150.0 \pm 5.5$ \\
\hline Energy intake, kcal/day & $98.00 \pm 0.65^{\#}$ & $99.90 \pm 0.40$ & $103.00 \pm 0.50$ & $105.00 \pm 0.70^{\$}$ & $100.80 \pm 0.72$ & $103.00 \pm 0.67$ \\
\hline Relative liver weight, $\mathrm{g} / 100 \mathrm{~g}$ of body weight & $\mathrm{t} \quad 3.2 \pm 0.12$ & $2.6 \pm 0.09^{*}$ & $2.9 \pm 0.06$ & $2.5 \pm 0.09^{\wedge, \$}$ & $2.9 \pm 0.05^{\wedge}$ & $3.1 \pm 0.08^{\wedge}$ \\
\hline
\end{tabular}

Table 3. Body weight gain, energy intake and liver weight of rats fed low-fat and high-fat diets containing lard, sunflower oil or menhaden oil

mean \pm SEM $(n=12) ;{ }^{*}-P<0.01$ vs other low-fat diets; ${ }^{\wedge}-P<0.001$ vs corresponding low-fat diet; ${ }^{*}-P<0.05$ vs corresponding high-fat diet; ${ }^{\$}-P<0.05$ vs other high-fat diets 
Table 4. Concentration of plasma lipids in rats fed low- and high-fat diets containing lard, sunflower oil or menhaden oil

\begin{tabular}{|c|c|c|c|c|c|c|}
\hline \multirow{2}{*}{ Indices } & \multicolumn{3}{|l|}{ Low-fat diets } & \multicolumn{3}{|l|}{ High-fat diets } \\
\hline & lard & sunflower oil & menhaden oil & lard & sunflower oil & menhaden oil \\
\hline NEFA, mEq/l & $0.37 \pm 0.02$ & $0.35 \pm 0.03$ & $0.32 \pm 0.04$ & $0.35 \pm 0.04^{*}$ & $0.25 \pm 0.01$ & $0.28 \pm 0.02$ \\
\hline $\mathrm{TG}, \mathrm{mg} / \mathrm{dl}$ & $69.00 \pm 6.14$ & $68.43 \pm 3.25$ & $33.14 \pm 3.53^{\wedge}$ & $82.00 \pm 5.74$ & $66.43 \pm 3.16$ & $25.86 \pm 3.76^{*}$ \\
\hline TC, mg/dl & $96.00 \pm 3.26$ & $89.71 \pm 2.62$ & $66.14 \pm 2.85^{\wedge}$ & $91.14 \pm 3.16$ & $84.86 \pm 1.41$ & $55.29 \pm 2.00^{*}$ \\
\hline $\mathrm{HDL}-\mathrm{C}, \mathrm{mg} / \mathrm{dl}$ & $63.78 \pm 3.40$ & $62.34 \pm 1.56$ & $45.67 \pm 3.29^{\wedge}$ & $58.30 \pm 3.44$ & $60.37 \pm 1.77$ & $36.77 \pm 3.15^{\star}$ \\
\hline LDL-C, mg/dl & $20.08 \pm 3.36$ & $14.60 \pm 1.49$ & $13.86 \pm 1.53$ & $17.87 \pm 1.93$ & $12.63 \pm 1.01$ & $12.70 \pm 2.22$ \\
\hline
\end{tabular}

NEFA - non-estrified fatty acids; TG - triglycerides; TC - total cholesterol; HDL-C - high-density lipoprotein cholesterol; LDL-C - low density lipoprotein cholesterol; mean \pm SEM $(n=6-9) ;{ }^{*}-P<0.05$ vs other high-fat diets; ${ }^{\wedge}-P<0.001$ vs other low-fat diets

Table 5. Results of two-way analysis of variance (ANOVA) of plasma lipids

\begin{tabular}{|c|c|c|c|c|c|c|}
\hline Indices & Effect & NEFA & TG & $\mathrm{TC}$ & HDL-C & LDL-C \\
\hline \multirow[t]{5}{*}{ Fat type } & SS & 0.0336 & 16436 & 8286 & 3530 & 270.9 \\
\hline & DF & 2 & 2 & 2 & 2 & 2 \\
\hline & MS & 0.0168 & 8218 & 4143 & 1765 & 135.4 \\
\hline & $\mathrm{F}$ & $F(2,36)=2.880$ & $F(2,35)=63.99$ & $F(2,35)=89.56$ & $F(2,34)=32.79$ & $F(2,34)=5.249$ \\
\hline & $P$-value & 0.0691 & $<0.0001$ & $<0.0001$ & $<0.0001$ & 0.0103 \\
\hline \multirow{5}{*}{$\begin{array}{l}\text { Fat level in diet } \\
\text { (LF \& HF diets) }\end{array}$} & SS & 0.02987 & 15.71 & 479.8 & 295.5 & 31.52 \\
\hline & DF & 1 & 1 & 1 & 1 & 1 \\
\hline & MS & 0.02987 & 15.71 & 479.8 & 295.5 & 31.52 \\
\hline & $\mathrm{F}$ & $F(1,36)=5.120$ & $F(1,35)=0.1223$ & $F(1,35)=10.37$ & $F(1,34)=5.490$ & $F(1,34)=1.221$ \\
\hline & $P$-value & 0.0298 & 0.7286 & 0.0028 & 0.0251 & 0.2769 \\
\hline \multirow[t]{5}{*}{ Interaction } & SS & 0.01213 & 753.9 & 81.59 & 79.62 & 2.007 \\
\hline & DF & 2 & 2 & 2 & 2 & 2 \\
\hline & MS & 0.006067 & 377.0 & 40.80 & 39.81 & 1.004 \\
\hline & $\mathrm{F}$ & $F(2,36)=1.040$ & $F(2,35)=2.935$ & $F(2,35)=0.8819$ & $F(2,34)=0.7397$ & $F(2,34)=0.3889$ \\
\hline & $P$-value & 0.3638 & 0.0663 & 0.4230 & 0.4848 & 0.9619 \\
\hline
\end{tabular}

NEFA - non-estrified fatty acids; TG - triglycerides; TC - total cholesterol; HDL-C - high-density lipoprotein cholesterol; LDL-C - low density lipoprotein cholesterol; LF - low fat; HF - high fat; SS - sum of squares; DF - degrees of freedom; MS - mean squares; $F$ - F-ratio; $P$-value - probability value

\section{Plasma glucose, insulin concentrations and HOMA-IR index}

Plasma glucose level (Figure 1A) was significantly lowered in rats fed low-fat diet with menhaden oil compared to other low-fat diets $(P<0.05)$; however it was significantly increased in rats fed high-fat diet with menhaden oil as compared either to low-fat diet with the same fat source $(P<0.01)$ or to the other isocaloric high-fat diets $(P<0.05)$.

There was no effect of fat type on insulin plasma concentration when rats were fed low- and high-fat diets. The insulin level was significantly increased in rats fed high-fat diets regardless used fat type in comparison to the corresponding low-fat diets $(P<0.01)$.

The HOMA-IR index was 3 times higher in rats fed high-fat diet with menhaden oil than in those fed corresponding low-fat diet $(P<0.01)$. On the other hand when rats were fed low-fat diets the
HOMA-IR index was the lowest in the animals fed diet with menhaden oil $(P<0.05)$.

The two-way ANOVA revealed no significant interaction between fat type and fat level in diet insulin levels $(\mathrm{F}(2,30)=0.1029 ; P=0.9026)$ and HOMA-IR index $(\mathrm{F}(2,30)=3.293 ; P=0.051)$. Main effect was confirmed only for fat level in diet (insulin, $\mathrm{F}(1,30)=30.28 ; P<0.0001$; HOMA-IR index, $\mathrm{F}(1,30)=38.27 ; P<0.0001)$, but not for fat type (insulin, $\mathrm{F}(2,30)=0.6330$, $P=0.5380$; HOMA-IR index, $\mathrm{F}(2,30)=1.204$; $P=0.3141)$. Furthermore, the effect of fat level (F ( 1 , $30)=14.53 ; P=0.006)$, and the interactivein level effect of fat type and fat level in $\operatorname{diet}(\mathrm{F}(2,30)=4.405$; $P=0.001)$ ) on glucose levels were confirmed by the two-way ANOVA. These results demonstrate that fat type and fat level were independent factors which affected plasma insulin levels and HOMA-IR index, but these factors showed the strong interaction in their effect on plasma glucose levels. 

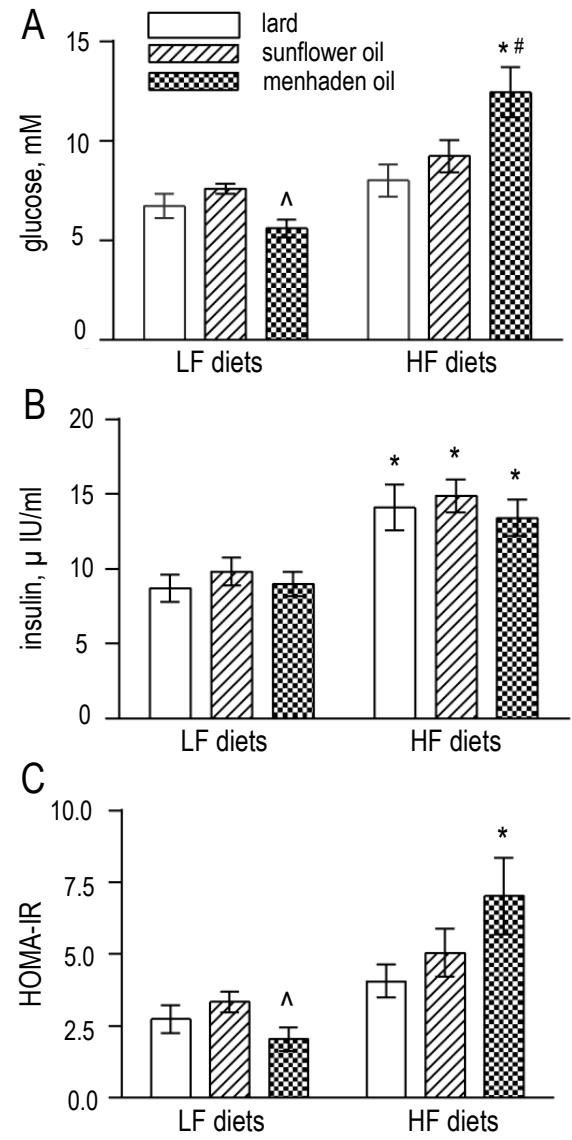

Figure 1. Effect of 6-week feeding with lard, sunflower oil or menhaden oil in low- and high-fat diets (LF and HF, respectively) on plasma concentrations of glucose (A) and insulin (B), and HOMA-IR (Homeostatic Model Assessment - Insulin Resistance) index (C) in non-genetically modified rats

data shown as mean \pm SEM $(n=6-9) ;{ }^{*}-P<0.01$ vs corresponding low-fat diet; ${ }^{\wedge}-P<0.05$ vs other low-fat diets; ${ }^{\#}-P<0.05$ vs other high-fat diets

\section{Discussion}

In the present study it was revealed that feeding rats with menhaden oil in a high-fat diet caused an increase in plasma glucose and insulin levels, as well as increased HOMA-IR index in comparison to low-fat diet. It was previously demonstrated that a high-PUFA diet caused hyperglycemia and obesity (Ikemoto et al., 1995), even when $7 \%$ of dietary saturated fatty acids in a high-fat diet was replaced by fish oil (Holness et al., 2004). More recently, Lionetti et al. (2014) reported hyperglycemic effect of high-fat diet with fish oil associated with the increased HOMA-IR index. In that study it was also shown that the liver mass was increased after feeding high-fat diet with fish oil in comparison to regular diet, although the highest liver mass was noted in group fed high-fat diet with lard. This is in contrast to our results, because the highest liver mass in our study was determined in animals fed high-fat diet with menhaden oil. The reason of this discrepancy can arise from the type of fish oil used to prepare diets. Cod oil, used in the above mentioned dietary study, has different ratio of n-3 PUFAs to other fatty acids than menhaden oil. It is well known that a high-fat diet contributes to insulin resistance resulting from fat accumulation in the liver (Wiedemann et al, 2013). The molecular mechanism of hepatic insulin resistance in rats fed high-fat diet involves the downstream phosphoinositide3-kinase (PI3K) /Akt pathway (Boucher et al., 2014) and it was demonstrated that a high n-3 PUFA diet completely abolished insulin receptor substrate 1 (IRS-1) tyrosine phosphorylation and PI3K activity in the liver and reduced the number of insulin receptors (Taouis et al., 2002).

Among disadvantages of high ingestion of fish oil is increased lipid peroxidation, since docosahexaenoic acid (DHA) is highly susceptible to peroxidation both in the plasma and in the liver. The PUFA peroxidation products, 4-hydroxy-2E-hexenal (4-HHE), a derivative of n-3 PUFAs, and 4-hydroxy-2E-nonenal (4HNE), a derivative of n-6 PUFAs, are accumulated in the cell membranes (Cohen et al., 2013). The insulin resistance in rats fed high-fat diet with menhaden oil in our study may result from increased formation of n-3 PUFA peroxidation by-products, which blunted insulin sensitivity. Recently, an impaired glucose uptake and insulin action by 4-HHE in the muscle cells, and significantly increased plasma 4-HHE levels in patients with type 2 diabetes as compared to healthy individuals has been reported (Soulage et al., 2018). Deleterious effects of n-3 PUFAs might depend on a dose of ingested fatty acid because a high dose of DHA (800-1600 mg/day) significantly increased 4-HHE in human plasma (Guillot et al., 2009), while a moderate dose $(400 \mathrm{mg} /$ day $)$ improved platelet function and induced antioxidant effects in diabetic patients (Véricel et al., 2015).

In our study TC, HDL cholesterol and TG plasma levels in rats fed both, low- and high-fat diets with menhaden oil were considerably lower than in rats fed the isocaloric diets based on lard or sunflower oil, and also in animals fed standard chow diet (results not shown). Gondim et al. (2018) also demonstrated that supplementation of $10 \%$ of energy by fish oil was enough to lower plasma lipid levels. It was also revealed that this hypolipidemic effect increased in line with increasing fish oil content in a diet. The lowering of plasma cholesterol by dietary n-3 PUFAs can be achieved by divergent metabolic pathways: by accelerated clearance of chylomicrons 
rich in n-3 PUFAs in the liver (Griffo et al., 2014), by increased cholesterol secretion into bile (Morgado et al., 2005), or reduced cholesterol biosynthesis in the liver through inhibition of sterol regulatory element binding protein-1c and the suppression of hepatic lipogenic enzymes (Deng et al., 2015). The hypotriglyceridemic effect of dietary menhaden oil could be triggered by decreased production and/or increase in clearance of very low-density lipoproteins (VLDL) and chylomicrons, which mainly transport triglycerides in plasma. Feeding with diets with fish oil is associated with a decrease in plasma NEFA levels, and also with suppression of Apo-B100 synthesis in the liver (Hashimoto et al., 2013), which results in an inhibition of VLDL production and secretion.

\section{Conclusions}

Feeding non-genetically modified rats a high-fat diet with menhaden oil resulted in lower plasma lipidemic parameters but increased plasma glucose level and decreased insulin sensitivity when compared to rats fed isocaloric diets with either sunflower oil and lard oil rich in n-6 polyunsaturated fatty acids (sunflower oil) or rich in saturated and monounsaturated fatty acids lard. Although the precise mechanism responsible for the insulin resistance in rodents fed a high-fat diet with fish oil is not fully elucidated, the obtained results are important in the discussion on diet supplementation with a high percentage of energy from fish oil since such a diet can disturb glucose homeostasis.

\section{Acknowledgements}

The authors thank A. Urbanska for assistance in biochemical determinations and A. Sarniak, A. Kliszko and Z. Sedzinska for technical assistance. The study was supported by the State Committee for Scientific Research, Poland (grant No. 0214/P05/2002/23) and the Medical University of Lodz (grant No. 503/0-079-04/503-01-001).

\section{References}

Akinkuolie A.O., Ngwa J.S., Meigs J.B., Djoussé L., 2011. Omega-3 polyunsaturated fatty acid and insulin sensitivity: A metaanalysis of randomized controlled trials. Clin. Nutr. 30, 702-707, https://doi.org/10.1016/j.clnu.2011.08.013

Baum S.J., Kris-Etherton P.M., Willett W.C., Lichtenstein A.H., Rudel L.L., Maki K.C., Whelan J., Ramsden C.E., Block R.C., 2012. Fatty acids in cardiovascular health and disease: A comprehensive update. J. Clin. Lipidol. 6, 216-234, https:// doi.org/10.1016/j.jacl.2012.04.077
Boucher J., Kleinridders A., Kahn C.R., 2014. Insulin receptor signaling in normal and insulin-resistant states. Cold Spring Harb. Perspect. Biol. 6, a009191, https://doi.org/10.1101/ cshperspect.a009191

Buettner R., Schölmerich J., Bollheimer L.C., 2007. High-fat diets: modeling the metabolic disorders of human obesity in rodents. Obesity 15, 798-808, https://doi.org/10.1038/oby.2007.608

Cameron T., Ghosh S., 2013. A high omega-6 PUFA diet impairs hepatocyte insulin signalling during diet-induced obesity. Can. J. Diabetes 37, S65, https://doi.org/10.1016/j.jcjd.2013.08.195

Chen C., Yang Y., Yu X., Hu S., Shao S., 2017. Association between omega-3 fatty acids consumption and the risk of type 2 diabetes: A meta-analysis of cohort studies. J. Diabetes Investig. 8, 480-488, https://doi.org/10.1111/jdi.12614

Cohen G., Riahi Y., Sunda V., Deplano S., Chatgilialoglu C., Ferreri C., Kaiser N., Sasson S., 2013. Signaling properties of 4-hydroxyalkenals formed by lipid peroxidation in diabetes. Free Radic. Biol. Med. 65, 978-987, https://doi.org/10.1016/j. freeradbiomed.2013.08.163

Deng X., Dong Q., Bridges D., Raghow R., Park E.A., Elam M.B., 2015. Docosahexaenoic acid inhibits proteolytic processing of sterol regulatory element-binding protein-1c (SREBP1c) via activation of AMP-activated kinase. Biochim. Biophys. Acta 1851, 1521-1529, https://doi.org/10.1016/j. bbalip.2015.08.007

Dziedzic B., Szemraj J., Bartkowiak J., Walczewska A., 2007. Various dietary fats differentially change the gene expression of neuropeptides involved in body weight regulation in rats. J. Neuroendocrinol. 19, 364-373, https://doi.org/10.1111/ j.1365-2826.2007.01541.x

Gondim P.N., Rosa P.V., Okamura D., Silva V.D.O., Andrade E.F., Biihrer D.A., Pereira L.J., 2018. Benefits of fish oil consumption over other sources of lipids on metabolic parameters in obese rats. Nutrients 10, E65, https://doi.org/10.3390/nu10010065

Griffo E., Di Marino L., Patti L. et al., 2014. Test meals rich in marine long-chain $n-3$ polyunsaturated fatty acids increase postprandial chylomicron response. Nutr. Res. 34, 661-666, https://doi.org/10.1016/j.nutres.2014.07.005

Guillot N., CailletE., Laville M., Calzada C., Lagarde M., Véricel E., 2009. Increasing intakes of the long-chain $\omega-3$ docosahexaenoic acid: effects on platelet functions and redox status in healthy men. FASEB J. 23, 2909-2916, https://doi.org/10.1096/fj.09-133421

Hashimoto Y., Yamada K., Tsushima H., Miyazawa D., Mori M., Nishio K., Ohkubo T., Hibino H., Ohara N., Okuyama H., 2013. Three dissimilar high fat diets differentially regulate lipid and glucose metabolism in obesity-resistant Slc:Wistar/ ST rats. Lipids 48, 803-815, https://doi.org/10.1007/s11745013-3805-3

Holness M.J., Smith N.D., Greenwood G.K., Sugden M.C., 2004. Acute $\omega-3$ fatty acid enrichment selectively reverses high-saturated fat feeding-induced insulin hypersecretion but does not improve peripheral insulin resistance. Diabetes 53, S166-S171, https://doi.org/10.2337/diabetes.53.2007.S166

Ikemoto S., Thompson K.S., Takahashi M., Itakura H., Lane M.D., Ezaki O., 1995. High fat diet-induced hyperglycemia: prevention by low level expression of a glucose transporter (GLUT4) minigene in transgenic mice. Proc. Natl. Acad. Sci. USA 92, 3096-3099, https://doi.org/10.1073/pnas.92.8.3096

Itsiopoulos C., Marx W., Mayr H.L., Tatucu-Babet O.A., Dash S.R., George E.S., Trakman G.L., Kelly J.T., Thomas C.J., Brazionis L., 2018. The role of omega-3 polyunsaturated fatty acid supplementation in the management of type 2 diabetes mellitus: A narrative review. J. Nutr. Intermed. Metabol. 14, 42-51, https://doi.org/10.1016/j.jnim.2018.02.002 
Jump D.B., Tripathy S., Depner C.M., 2013. Fatty acid-regulated transcription factors in the liver. Annu. Rev. Nutr. 33, 249-269, https://doi.org/10.1146/annurev-nutr-071812-161139

Lanza I.R., Blachnio-Zabielska A., Johnson M.L., Schimke J.M., Jakaitis D.R., Lebrasseur N.K., Jensen M.D., Sreekumaran Nair K., Zabielski P., 2013. Influence of fish oil on skeletal muscle mitochondrial energetics and lipid metabolites during high-fat diet. Am. J. Physiol. Endocrinol. Metab. 304, E1391E1403, https://doi.org/10.1152/ajpendo.00584.2012

Lee J.S., Pinnamaneni S.K., Eo S.J., Cho I.H., Pyo J.H., Kim C.K., Sinclair A.J., Febbraio M.A., Watt M.J., 2006. Saturated, but not $n-6$ polyunsaturated, fatty acids induce insulin resistance: role of intramuscular accumulation of lipid metabolites. J. Appl. Physiol. 100, 1467-1474, https://doi.org/10.1152/ japplphysiol.01438.2005

Lionetti L., Mollica M.P., Donizzetti I. et al., 2014. High-lard and highfish-oil diets differ in their effects on function and dynamic behavior of rat hepatic mitochondria. PLoS ONE 24, e92753, https://doi.org/10.1371/journal.pone.0092753

Liu X., Xue Y., Liu C., Lou Q., Wang J., Yanagita T., Xue C., Wang Y., 2013. Eicosapentaenoic acid-enriched phospholipid ameliorates insulin resistance and lipid metabolism in dietinduced-obese mice. Lipids Health Dis. 12, 109, https://doi. org/10.1186/1476-511X-12-109

Morgado N., Rigotti A., Valenzuela A., 2005. Comparative effect of fish oil feeding and other dietary fatty acids on plasma lipoproteins, biliary lipids, and hepatic expression of proteins involved in reverse cholesterol transport in the rat. Ann. Nutr. Metab. 49 397-406, https://doi.org/10.1159/000088935

Silva Figueiredo P., Carla Inada A., Marcelino G., Maiara Lopes Cardozo C., de Cássia Freitas K., de Cássia Avellaneda Guimarães R., Pereira de Castro A., Aragão do Nascimento V., Aiko Hiane P., 2017. Fatty acids consumption: the role metabolic aspects involved in obesity and its associated disorders. Nutrients 9, 1158, https://doi.org/10.3390/nu9101158
Siri-Tarino P.W., Sun Q., Hu F.B., Krauss R.M., 2010. Saturated fatty acids and risk of coronary heart disease: modulation by replacement nutrients. Curr. Atheroscler. Rep. 12, 384-390, https://doi.org/10.1007/s11883-010-0131-6

Soulage C.O., Sardón Puig L., Soulère L., Zarrouki B., Guichardant M., Lagarde M., Pillon N.J., 2018. Skeletal muscle insulin resistance is induced by 4-hydroxy-2-hexenal, a by-product of n-3 fatty acid peroxidation. Diabetologia 61, 688-699, https:// doi.org/10.1007/s00125-017-4528-4

Taouis M., Dagou C., Ster C., Durand G., Pinault M., Delarue J., 2002. $\mathrm{N}-3$ polyunsaturated fatty acids prevent the defect of insulin receptor signaling in muscle. Am. J. Physiol. Endocrinol. Metab. 282, E664-E671, https://doi.org/10.1152/ajpendo.00320.2001

Tekeleselassie A.W., Rajion M.A., Goh Y.M., Moteshakeri M., Soleimani A.F, Ebrahimi M., 2014. High-fat diets rich in n-3 polyunsaturated fatty acids delay onset of insulin resistance in rats. Pak. J. Nutr. 13, 223-233, https://doi.org/10.3923/ pjn.2014.223.233

Véricel E., Colas R., Calzada C., Lê Q.H., Feugier N., Cugnet C., Vidal H., Laville M., Moulin P., Lagarde M., 2015. Moderate oral supplementation with docosahexaenoic acid improves platelet function and oxidative stress in type 2 diabetic patients. Thromb. Haemost. 114, 289-296, https://doi.org/10.1160/ TH14-12-1003

Wiedemann M.S.F., Wueest S., Item F., Schoenle E.J., Konrad D., 2013. Adipose tissue inflammation contributes to short-term high-fat diet-induced hepatic insulin resistance. Am. J. Physiol. Endocrinol. Metab. 305, E388-E395, https://doi.org/10.1152/ ajpendo.00179.2013 